\title{
Infarct size by SS-SSFP vs. IR-GRE: influence of imaging time after contrast administration and infarct age, and implications for clinical trials
}

\author{
Elisa McAlindon ${ }^{*}$, Chris Lawton, Nauman Ahmed, Nathan Manghat, Mark Hamilton, Chiara Bucciarelli-Ducci \\ From 17th Annual SCMR Scientific Sessions \\ New Orleans, LA, USA. 16-19 January 2014
}

\section{Background}

Myocardial late gadolinium enhancement (LGE) imaging is conventionally acquired using a gradient-echo inversion recovery (IR-GRE) sequence 15-20 min after contrast administration. However, this method can be limited by poor breath holding or arrhythmias. Freebreathing single shot steady state free precession (SSSSFP) sequence is an alternative LGE imaging technique which can overcome some of the IR-GRE limitations but at the expense of lower resolution. The ideal imaging timing for LGE SS-SSFP, and whether it can be used interchangeably with IR-GRE has not yet been established. The aim of our study was to investigate acute and chronic infarct size: 1) Comparing LGE by SS-SSFP vs. IR-GRE at $15 \mathrm{~min}$. 2) Comparing LGE SSSSFP imaging at 5 vs. 10 vs. 15 min after contrast administration vs. IR-GRE at $15 \mathrm{~min}$.

\section{Methods}

36 patients were prospectively recruited for CMR day 2 and 3 months following reperfused STEMI. IR-GRE images were acquired 15 minutes following gadolinium contrast administration (Gadovist $0.1 \mathrm{mmol} / \mathrm{kg}$ ). Freebreathing SS-SSFP images were obtained 5, 10 and 15 min following contrast. LGE was calculated and infarct size was expressed in grams. Agreement between the 2 sequences was assessed by the Bland Altman method. Differences between time following contrast for both acute and chronic infarct size were assessed using paired t-tests. All patients provided informed written consent and the study was approved by the regional ethics committee.

CMR Unit, NIHR Bristol Cardiovascular Biomedical Research Unit, Bristol, UK

\section{Results}

When imaging 15 min after contrast administration, there was a significant difference in acute infarct mass using SS-SSFP vs. GRE-IR ( $\mathrm{p}=0.006)$, whilst there was no difference in chronic infarct mass $(\mathrm{p}=0.54)$ (Table 1$)$. Bland Altman agreement with IR-GRE was best for chronic infarct (chronic infarct bias $-0.81 \mathrm{~g}$, acute infarct bias $-7.08 \mathrm{~g}$ ). When imaging using SS-SSFP in acute infarct at multiple time points, there was no difference between imaging at 5 or $10 \mathrm{~min}(\mathrm{p}=0.13)$, but there was a significant difference between 10 and $15 \mathrm{~min}(\mathrm{p}=0.02)$ and 5 and $15 \mathrm{~min}(\mathrm{p}=0.01)$ (Table 2). When imaging LGE with SS-SSFP in chronic infarct at multiple time points, the only significant difference was noted between 5 and $15 \min (\mathrm{p}=0.04)$ (Table 2).

\section{Conclusions}

Our study demonstrates both acute and chronic infarct size with SS-SSFP changes significantly between 5 vs. 10 vs. 15 min, demonstrating that the time of imaging after contrast administration is important for this sequence too. The ideal timing for imaging acute and chronic infarct size by SS-SSFP and IR-GRE are different. In particular, when imaging at $15 \mathrm{~min}$ after contrast, LGE by SS-SSFP can underestimate acute infarct size. In chronic infarctions time after contrast injection for LGE by SS-SSFP seems less critical but infarct size at $15 \mathrm{~min}$

Table 1 LGE Imaging by SS-SSFP vs. IR-GRE 15 min after contrast administration.

\begin{tabular}{cccc}
\hline LGE Imaging & $\begin{array}{c}\text { SS-SSFP } \\
\mathbf{1 5} \mathbf{~} \mathbf{~ i n}\end{array}$ & $\begin{array}{c}\text { IR-GRE } \\
\mathbf{1 5} \mathbf{~} \text { in }\end{array}$ & p value \\
\hline Acute Infarct & $28.65 \mathrm{~g}$ & $35.7 \mathrm{~g}$ & $\mathrm{p}=0.006$ \\
\hline Chronic Infarct & $16.3 \mathrm{~g}$ & $15.5 \mathrm{~g}$ & $\mathrm{p}=0.54$ \\
\hline
\end{tabular}


Table 2 LGE Imaging by SS-SSFP at multiple time points after contrast administration.

\begin{tabular}{|c|c|c|c|c|}
\hline & $5 \mathrm{~min}$ & $10 \mathrm{~min}$ & $15 \mathrm{~min}$ & $p$ value \\
\hline Acute Infarct & $32.8 \mathrm{~g}$ & $31.1 \mathrm{~g}$ & $28.6 \mathrm{~g}$ & $\begin{array}{c}5 \text { vs } 10 \min p=0.13 \\
10 \text { vs } 15 \min p=0.02 \\
5 \text { vs } 15 \min p=0.01\end{array}$ \\
\hline Chronic Infarct & $18.6 \mathrm{~g}$ & $17.4 \mathrm{~g}$ & $16.3 \mathrm{~g}$ & $\begin{aligned} 5 \text { vs } 10 \min p & =0.09 \\
10 \text { vs } 15 \min p & =0.35 \\
5 \text { vs } 15 \min p & =0.04\end{aligned}$ \\
\hline
\end{tabular}

best correlated with LGE by IR-GRE. LGE by SS-SSP offers a valid alternative in clinical practice for the (visual) assessment of myocardial infarction but in clinical trials it should not be used interchangeably with LGE IR-GRE

\section{Funding}

This work was funded by the NIHR Bristol Cardiovascular Biomedical Research Unit.

Published: 16 January 2014

doi:10.1186/1532-429X-16-S1-P183

Cite this article as: McAlindon et al:: Infarct size by SS-SSFP vs. IR-GRE:

influence of imaging time after contrast administration and infarct age, and implications for clinical trials. Journal of Cardiovascular Magnetic

Resonance 2014 16(Suppl 1):P183.

Submit your next manuscript to BioMed Central and take full advantage of:

- Convenient online submission

- Thorough peer review

- No space constraints or color figure charges

- Immediate publication on acceptance

- Inclusion in PubMed, CAS, Scopus and Google Scholar

- Research which is freely available for redistribution

Submit your manuscript at www.biomedcentral.com/submit 